\title{
Update on the NAS-NRC Twin Registry
}

\author{
William F. Page \\ Medical Follow-up Agency, Institute of Medicine, Washington DC, United States of America
}

\begin{abstract}
$T_{\text {he }}^{\text {he }}$ he National Academy of Sciences-National Research Council (NAS-NRC) Twin Registry is one of the oldest, national population-based twin registries in the United States. It consists of 15,924 white male twin pairs born in the years 1917 to 1927 (inclusive), both of whom served in the armed forces, mostly during World War II. This article updates activity in this registry since the earlier 2002 article in Twin Research. The results of clinically based studies on dementia, Parkinson's disease, age-related macular degeneration, and primary osteoarthritis were published, as well as articles based on previously collected questionnaire data on chronic fatigue syndrome, functional limitations, and healthy aging. In addition, risk factor studies are being planned to merge clinical data with earlier collected risk factor data from questionnaires. Examination data from the subset of National Heart, Lung, and Blood Institute (NHLBI) twins resulted in a number of articles, including the relationship of endogenous sex hormones to coronary heart disease and morphological changes in aging brain structures. The NEO Five-Factor Personality Inventory (a paper-and-pencil self-administered questionnaire) has been fielded for the first time. A push to consolidate the various data holdings of the registry is being made.
\end{abstract}

The National Academy of Sciences-National Research Council (NAS-NRC) Twin Registry is one of the largest twin registries in the United States and is a national, rather than regional or state, registry. The registry is a program of the Medical Follow-Up Agency, a division of the Institute of Medicine, which is part of the National Academies. The Institute of Medicine was chartered in 1970 as a national institution committed to the advancement of health sciences and education and to the improvement of health care.

\section{Clinically Based Studies}

Studies of chronic disease outcomes remain an important focus of the NAS-NRC Twin Registry. In many cases, simple questionnaire follow-up will not provide sufficient data, and clinical examination data must be collected. Both Alzheimer's disease/dementia and Parkinson's disease have been the topic of decades-long investigation and of recent papers (Marras et al., 2005; Potter et al., 2004; Steffens et al., 2005). A separate article in this volume deals with studies of Alzheimer's disease and dementia in the NAS-NRC Twin Registry
(Plassman et al., 2006). Two recent investigations used a two-stage data collection process and a corresponding bivariate analysis of screening and examination data. For the study of age-related macular degeneration (Seddon et al., 2005), examination data included fundus photographs, which were collected and read, and for the study of primary osteoarthritis of the hip (Page et al., 2003), examination data included x-rays.

DNA data constitute a special subset of clinical data. In a study of healthy aging, subjects were screened using a mail questionnaire, and the heritability of healthy physical aging was studied (Reed \& Dick, 2003). Clinical follow-up involved obtaining and analyzing DNA from blood specimens, and a genomewide scan found a locus near D4S1564 associated with healthy aging (Reed et al., 2004).

Finally, many of the registry's clinical studies collect DNA not only for study-specific purposes, but also to validate or determine zygosity. Using pooled data from a number of studies, zygosity was validated in $96.8 \%$ of twins with a specified zygosity, and the group of twins with missing zygosity data were found to contain roughly equal numbers of monozygous and dizygous twins (Reed et al., 2005).

\section{The National Heart, Lung, and Blood Institute (NHLBI) Subsample}

In the 1960s, a sample of 514 twin pairs from the registry was selected for examination under the sponsorship of the National Heart, Lung, and Blood Institute (NHLBI) of the National Institutes of Health. The twin pairs were originally selected for their proximity (within 200 miles) to one of five study centers (Framingham, Massachusetts; Indianapolis, Indiana; Davis, San Francisco, or Los Angeles, California), and six examinations of this group have been made: in 1969 to 1973,1981 to 1982,1986 to 1987, 1995 to 1997,1999 to 2001 , and 2002 to 2003. Although the NHLBI subsample was initiated to study the genetics of cardiovascular disease, the longitudinal examination data have been the basis of many important clinical studies in noncardiovascular disease topics.

Received 20 May, 2006; accepted 31 July, 2006.

Address for correspondence: William Page, Institute of Medicine (Keck 776), 500 Fifth Street, NW, Washington, DC 20001, USA. E-mail:wpage@nas.edu 
The last three examinations have collected MRI data, and DNA from the third clinical examination has been analyzed for markers such as Apo E4. Recent work in the NHLBI sample includes studies of the relationship of endogenous sex hormones to coronary heart disease (Mikulec et al., 2004), heritability of plasma sex hormones (Ring et al., 2005), cardiovascular risk factors (Reed et al., 2003), sleep disorders (Carmelli et al., 2004), depressive symptoms (McCaffery, Niaura, Todaro, et al., 2003; McCaffery Niaura, Swan, et al., 2003), and aging brain morphology (Carmelli et al., 2002; Pfefferbaum et al., 2004).

\section{Questionnaire data}

Three major epidemiologic surveys have gathered data via mailed questionnaires. Questionnaire data were the basis for articles on the heritability of age-related functional impairment (Gurland et al., 2004), handedness (Jaffe et al., 2003), and chronic fatigue syndrome (Fitzpatrick et al., 2004), as well as a letter on stature and prostate cancer (Rohrmann et al., 2006a). A study on lower urinary tract symptoms (Rohrmann et al., 2006 b) is a model for further studies that will combine previously collected questionnaire data with more recently collected outcome data to permit an investigation of risk factors. Also, the 60-item NEO Five-Factor Personality Inventory was administered to some 1600 twins during 2005 and 2006. Investigations of the heritability of personality traits in older twins (now 79 to 89 years of age) are planned, as well as a number of investigations linking personality factors to health outcomes.

\section{Access to the Registry}

Access to the NAS-NRC Twin Registry is available to qualified researchers whose use of the Registry is deemed appropriate by the Medical Follow-up Agency's Twins Committee. The committee evaluates proposals according to the principles outlined above and may request supplemental information or make recommendations about technical aspects of the proposed study. Access to the registry is granted only upon approval by the committee.

Investigators are required to limit their contact with Registry subjects to that detailed in their application and to agree not to undertake any additional contact except upon submission and approval of a supplemental application. Initial solicitation of the twins is made under the Registry's auspices, and only if the twins consent to participate in a study may they be contacted subsequently by the investigators. The National Academies' Human Subjects Committee reviews and approves all twin studies that involve subject contact. All information obtained from the twins becomes part of the Registry and may be made available to future investigators.

As the registry receives no outside funding for its core program - obtaining current information, such as address, vital status, and cause of death, from various sources and updating the registry — investiga- tors are expected to contribute towards these expenses. Brief letters of interest outlining a proposed area of research within the Registry are welcomed and may be sent to the Director, NAS-NRC Twin Registry, Institute of Medicine (Keck 776), 500 Fifth Street, NW, Washington, DC 20001. If there are no current studies in the area of interest, a follow-up proposal will be solicited for review by the Twins Committee.

\section{Current Membership of the Twins Committee}

Irving Gottesman, Chair, University of Minnesota; John Breitner, Vice Chair, University of Washington; Paul Costa, National Institute on Aging; Danielle Dick, Washington University School of Medicine; Margaret Gatz, University of Southern California; Jack Goldberg, University of Washington; Andrew Heath, Washington University School of Medicine; Harold Snieder, University of Groningen.

\section{References}

Carmelli, D., Colrain, I. M., Swan, G. E., \& Bliwise, D. L. (2004). Genetic and environmental influences in sleepdisordered breathing in older male twins. Sleep, 27, 917-922.

Carmelli, D., Swan, G. E., DeCarli, C., \& Reed, T. (2002). Quantitative genetic modeling of regional brain volumes and cognitive performance in older male twins. Biological Psychology, 61, 139-155.

Fitzpatrick, A. L., Reed, T., Goldberg, J., \& Buchwald, D. (2004). The association between prolonged fatigue and cardiovascular disease in World War II veteran twins. Twin Research, 7, 571-577.

Gurland, B. J., Page, W. F., \& Plassman, B. L. (2004). A twin study of the genetic contribution to age-related functional impairment. Journal of Gerontology Series A: Biological Sciences and Medical Sciences, 59, 859-863.

Jaffe, J., Ross, D., Anderson, S. W., Beebe, B., \& SquiresWheeler, E. (2003). NAS/NRC Twin Registry. (2003). Incidence of nondextrality in the NAS/NRC Twin Registry. Perception and Motor Skills, 96, 963-964.

Marras, C., Goldman, S., Smith, A., Barney, P., Aston, D., Comyns, K., Korell, M., Langston, J. W., Ross, G. W., \& Tanner, C. M. (2005). Smell identification ability in twin pairs discordant for Parkinson's disease. Movement Disorders, 20, 687-693.

McCaffery, J. M., Niaura, R., Swan, G. E., \& Carmelli, D. (2003). A study of depressive symptoms and smoking behavior in adult male twins from the NHLBI twin study. Nicotine and Tobacco Research, 5, 77-83.

McCaffery, J. M., Niaura, R., Todaro, J. F., Swan, G. E., \& Carmelli, D. (2003). Depressive symptoms and metabolic risk in adult male twins enrolled in the National Heart, Lung and Blood Institute twin study. Psychosomatic Medicine, 65, 490-497.

Mikulec, K. H., Holloway, L., Krasnow, R. E., Javitz, H., Swan, G. E., Reed, T., Marcus, R., \& Carmelli, D. 
(2004). Relationship of endogenous sex hormones to coronary heart disease: a twin study. Journal of Clinical Endocrinology and Metabolism, 89, 1240-1245.

Page, W. F., Hoaglund, F. T., Steinbach, L. S., \& Heath, A. C. (2003). Primary osteoarthritis of the hip in monozygotic and dizygotic male twins. Twin Research, 6, 147-151.

Pfefferbaum, A., Sullivan, E. V., \& Carmelli, D. (2004). Morphological changes in aging brain structures are differentially affected by time-linked environmental influences despite strong genetic stability. Neurobiological Aging, 25,175-183.

Plassman, B. L., Steffens, D. C., Burke, J. R., WelshBohmer, K. A., Newman, T. N., Drosdick, D., Helms, M. J., Potter, G. G., \& Breitner, J. C. S. (2006). Duke twins study of memory and aging in the NAS-NRC Twin Registry. Twin Research and Human Genetics, 9, 950-957.

Potter, G. G., Plassman, B. L., Helms, M. J., Steffens, D. C., \& Welsh-Bohmer, K. A. (2004). Age effects of coronary artery bypass graft on cognitive status change among elderly male twins. Neurology, 63, 2211-2212.

Reed, T., Carmelli, D., Robinson, T. S., Rinehart, S. A., \& Williams, C. J. (2003). More favorable midlife cardiovascular risk factor levels in male twins and mortality after 25 years of follow-up is related to longevity of their parents. Journal of Gerontology Series A: Biological Sciences and Medical Sciences, 58, 367-371.

Reed, T., \& Dick, D. M. (2003). Heritability and validity of healthy physical aging (wellness) in elderly male twins. Twin Research, 6, 227-234.

Reed, T., Dick, D. M., Uniacke, S. K., Foroud, T., \& Nichols, W. C. (2004). Genome-wide scan for a healthy aging phenotype provides support for a locus near D4S1564 promoting healthy aging. Journals of Gerontology Series A: Biological Sciences and Medical Sciences, 59, 227-232.

Reed, T., Plassman, B. L., Tanner, C. M., Dick, D. M., Rinehart, S. A., \& Nichols, W. C. (2005). Verification of self-report of zygosity determined via DNA testing in a subset of the NAS-NRC twin registry 40 years later. Twin Research and Human Genetics, 8, 362-367.

Ring, H. Z., Lessov, C. N., Reed, T., Marcus, R., Holloway, L., Swan, G. E., \& Carmelli, D. (2005). Heritability of plasma sex hormones and hormone binding globulin in adult male twins. Journal of Clinical Endocrinology and Metabolism, 90, 3653-3658.

Rohrmann, S., Fallin, M. D., Page, W. F., Reed, T., Partin, A. W., \& Walsh, P. C. (2006a). Re: 'Obesity and hormone-dependent tumors: Cohort and co-twin control studies based on the Swedish twin registry'. International Journal of Cancer, 118, 785.

Rohrmann, S., Fallin, M. D., Page, W. F., Reed, T., Partin, A. W., Walsh, P. C., \& Platz, E. A. (2006b). Concordance rates and modifiable risk factors for lower urinary symptoms in twins. Epidemiology, 17, 419-427.

Seddon, J. M., Cote, J., Page, W. F., Aggen, S. H., \& Neale, M.C. (2005). The US Twin study of age-related macular degeneration: Relative roles of genetic and environmental influences. Archives of Ophthalmology, 123, 321-327.

Steffens, D. C., Maytan, M., Helms, M. J., \& Plassman, B. L. (2005). Prevalence and clinical correlates of neuropsychiatric symptoms in dementia. American Journal of Alzheimer's Disease and Other Dementias, 20, 367-373. 